\title{
ANÁLISE DOS PRINCIPAIS IMPACTOS QUE AFETAM A QUALIDADE DE VIDA DOS PROFESSORES DA REDE PÚBLICA DE ENSINO NO MUNICÍPIO DE OSÓRIO-RS
}

Leonardo Souza Campos ${ }^{1}$

Resumo: O presente trabalho descreve uma pesquisa que foi realizada em uma escola municipal da rede pública de ensino do município de Osório-RS, com o objetivo de analisar os principais impactos que afetam a qualidade de vida dos professores deste local, levando em consideração o alto índice de adoecimento de profissionais da área da educação. Para tanto, foram realizadas entrevistas com dez professores atuantes neste contexto, com tempo de exercício na profissão variável. O discurso dos professores revela que grande parte deles estão desmotivados com a carreira, sobretudo pela desvalorização profissional. Ademais, é apontado nessa pesquisa que os aspectos relacionados a baixa remuneração, acúmulo de atribuições e a falta de disciplina dos alunos estão entre os principais fatores que podem desencadear o mal-estar docente. Compreende-se a situação da educação na atualidade, em que a realidade lastimável de profissionais desvalorizados pela própria comunidade e o descaso dos nossos governantes acarreta em desgaste físico e psicológico dos professores, dificultando o avanço da educação.

Palavras-chave: Educação; Atividade docente; Qualidade de vida

\section{ANALYSIS OF MAIN IMPACTS THAT AFFECT THE QUALITY OF LIFE OF TEACHERS NETWORK PUBLIC EDUCATION IN THE MUNICIPALITY OF OSORIO-RS}

\begin{abstract}
The present work describes a research that was carried out in a municipal school of the public school system of the city of Osório-RS, aiming to analyze the main impacts that affect the quality of life of the teachers of this place, taking into consideration the high index. of illness in professionals on the education area. To this end, interviews were conducted with ten teachers working in this context, with length of exercise in the variable profession. The
\end{abstract}

\footnotetext{
${ }^{1}$ Acadêmico do Curso de Bacharelado em Psicologia da UNICNEC.
} 
teacher's discourse reveals that most of them are unmotivated with their career, mainly due to professional devaluation. Besides that, it is indicated in this research that aspects related to low remuneration, accumulation of duties and lack of discipline from the students are the main factors that can trigger the discomfort in the teacher's. Understand the situation of education today, in which the ultimate reality of professionals devalued by the community itself and the neglect of our leaders leads to the physical and psychological distress of teachers, hindering the advancement of education.

Keywords: Education; Teaching activity; Quality of life

\section{INTRODUÇÃO}

$\mathrm{Na}$ sociedade atual, o professor tem um papel fundamental e significativo na vida do educando, cuja eficácia deste trabalho garante aos alunos uma oportunidade de crescimento e aprendizagem plena. Dentre as profissões formais no Brasil, a pratica da docência no Ensino Fundamental e também no ensino Médio situa-se entre uma das que ostenta os maiores índices de degradação emocional para os trabalhadores (REIS, ARAUJO, CARVALHO, BARBALHO, \& SILVA, 2006). Aos educadores, sua função tradicional era o ensino de disciplinas, tendo migrado gradativamente para assumir funções como construir hábitos de saúde, prestar auxílio psicológico, terminando por ficarem sobrecarregados com questões burocráticas (SANTOME, 2001).

Segundo (GOLDBERG ET AL., 1997), a saúde emocional é percebida como uma avaliação pessoal do sujeito sobre suas experiências de tensão emocional, depressão, ansiedade, sintomas somáticos, habilidades sociais e competências para lidar com situações conflitantes. Os professores formam uma categoria profissional exposta a diversos riscos psicossociais, em decorrência da complexa organização escolar e por se depararem diariamente com situações que desequilibram suas expectativas e causam esgotamento mental.

A realidade tem mostrado que a influência do papel do professor na vida do aluno vai além de alfabetizar, o educador muitas vezes tem preenchido lacunas que fogem do âmbito 
escolar. Cabe ao professor, também, fazer o planejamento de atividades extraescolares, comparecer em reuniões pedagógicas, workshops, conselhos de classe, elaborar atividades de recuperação, preenchimento de relatórios referentes às dificuldades de aprendizagem dos alunos (ESTEVE, 1999; NACARATO, VARANI \& CARVALHO, 2000; SCHNETZLER, 2000; WOODS, 1999). Logo, a escolha deste tema visa contribuir para fomentar maior interesse e discussão para quem acredita na educação escolar como crucial para formação do indivíduo enquanto cidadão. Levando em consideração a importância desta pesquisa, pois a profissão de educador leva consigo a missão de formar cidadãos aptos a atuarem de forma ética e funcional nas suas comunidades, este trabalho tem como finalidade descrever a problemática acerca dos possíveis impactos causados na prática da docência na rede pública de Ensino na cidade de Osório, e analisar de que forma as circunstâncias do ambiente de trabalho tem prejudicado a qualidade de vida desses professores.

Não existe atualmente um consenso quando se trata de definir qualidade de vida. De acordo com (FERNANDES, 1996), o conceito de qualidade de vida no trabalho não é algo unânime entre os teóricos, entretanto, indicadores como a satisfação dos indivíduos e boa produção da organização estão presentes na maioria dos estudos sobre qualidade de vida. Assim podem ser agrupados aspectos que envolvem o conceitual sobre qualidade de vida, tais como: a percepção do indivíduo sobre a sua realidade de vida no contexto cultural, o sistema de valores no qual está inserido e como se relaciona com seus objetivos, exigências, padrões e conflitos. Segundo (MORENO et al., 2006), o conceito amplo abrange a saúde física, o estado mental, nível de independência, interações sociais e o relacionamento do indivíduo com o ambiente.

Grande parte das pesquisas sobre qualidade de vida no trabalho está relacionada à humanização do trabalho e também na procura por práticas que têm resultados produtivos e satisfatórios para as empresas, levando-se em consideração a cooperação de todos os trabalhadores, a reestruturação de cargos e condições adequadas de trabalho para os indivíduos. As organizações motivadas pelas mudanças sociais, políticas e econômicas tendem a entender que a organização de mercado mais competitiva é a valorização dos recursos humanos, pois o vigor humano é a base de trabalho para se alcançar a produção e o desenvolvimento pretendidos. (SINHA, 2012; VALIZADEH, \& GHAHREMANI, 2012). (GORENAK E KOSIR, 2012), enfatizam que nem mesmo o equipamento mais avançado é 
capaz de garantir o sucesso de organizações se estas não tiverem pessoas envolvidas em realizar o trabalho necessário, o que beneficia os estudos sobre as relações empregado-organização.

A Organização Mundial da Saúde (OMS) aponta que aproximadamente 30\% dos trabalhadores funcionais, na população geral, padecem de transtornos mentais de menor intensidade, à medida que cerca de $5 \%$ a $10 \%$ sofrem de transtornos mentais graves (VASCONCELOS, 2010). Dentro desse contexto, estão incluídos os trabalhadores que exercem a função de docente na rede pública de ensino. A profissão de docente constitui, atualmente, uma atividade arriscada, pois se trata de uma das profissões mais estressantes na esfera do capitalismo vigente (SOUZA E LEITE, 2011), marcada pela extrema exploração da mão de obra e pela produção em larga escala de enfermidades, em que se destacam os transtornos mentais (BREILH E TILLERIA, 2009).

Atualmente os alunos, bem como a sociedade como um todo dependem da qualidade do serviço oferecido pelos professores para obterem uma boa formação escolar. Contudo, (GOES, 2014) afirma que "a desvalorização e a carência de reconhecimento da profissão, o acúmulo de carga de trabalho, o resultado da péssima remuneração, levam os professores a serem afetados pelo mal-estar docente". (ESTEVE, 1999) qualifica como mal-estar docente, um tipo de patologia social acarretada devido à falta de amparo da sociedade ao docente, ocasionando o desencantamento com o trabalho. Desta forma, a qualidade de ensino ofertada está diretamente ligada aos aspectos centrais do bem-estar dos educadores, sendo elementos fundamentais para a satisfação dos professores: salário justo, a estabilidade, a capacitação, a jornada de trabalho adequada, a dedicação exclusiva para uma escola apenas, o plano de carreira decente e a inclusão de hora-atividade grupal e individual. A falta de planos de carreira apropriados, bem como os baixos ordenados, leva o docente a vivenciar uma frustração relacionada ao seu trabalho. Essa decepção frequentemente resulta em uma naturalização dessa desvalorização pelo trabalho, deteriorando não somente a qualidade de vida dos trabalhadores envolvidos, como também a eficácia do ensino oferecido (GOUVEIA, 2006).

(CORTEZ E COLABORADORES, 2017), ao pesquisar artigos publicados entre 2003 e 2016 relacionados ao tema da saúde do trabalhador docente, localizaram 69 artigos elegíveis 
para o estudo. Com relação aos sintomas psíquicos referentes, prevaleceram depressão, estafa emocional, ansiedade, estresse, insônia, síndrome de Burnout, patologias mentais, abandono do trabalho, déficits na criatividade e no âmbito socioemocional, distorções na concepção da relevância e do esforço destinado ao trabalho, que induz o docente a se sujeitar a riscos e a sobrecarga. A mesma pesquisa, enfatizando a categoria 'características contextuais da atividade docente', reuniu trabalhos sobre a múltipla jornada, acúmulo de tarefas e problemas de relacionamento envolvendo famílias e a escola, demanda por altos padrões institucionais, pressão elevada por desempenho e níveis reduzidos de monitoramento das tarefas, indisciplina em sala de aula, barulhos, agressões entre alunos, burocratização, lotação de salas de aula e infraestrutura precária para o trabalho.

O trabalho docente é compreendido como uma atividade repetitiva, fragmentada e executada com a imposição de ritmos intensos. As análises sobre as condições de trabalho são fortemente marcadas pela autopercepção dos professores, sendo praticamente inexistentes os estudos empíricos sobre as reais condições de trabalho em escolas. Da mesma forma, há também poucos estudos sobre os reflexos da organização e da gestão do trabalho na saúde dos professores e os estudos sobre saúde, de forma geral, buscam os sintomas (autopercepção) e suas patologias e acabam por estabelecer orientações para a promoção e prevenção (SOUZA E LEITE, 2011, p. 1.106).

Segundo (GRANDA E BREILH, 1989) e (BREILH, 2006), para evoluir no entendimento da origem do adoecimento, é necessário investigar as dinâmicas particulares, pertinentes ao estilo de vida imposto a determinados grupos (classes ou frações de classes), que definem suas circunstâncias singulares de subsistência; trata-se portanto de uma multiplicidade de fatores determinados pelos processos de estruturação social.

Conforme (CRUZ E COLABORADORES, 2010), à docência é uma atividade que demanda atuação que frequentemente excede a jornada de trabalho formal e o ambiente físico das instituições de ensino. O professor se submete a elaborar atividades na própria casa, como correção de provas, desenvolver aulas, estudar e se qualificar, despendendo tempo de sua vida privada que poderia ser usado para o convívio com familiares, ou até mesmo para o lazer. $\mathrm{O}$ texto apresentado teve como ambição abordar aspectos referentes a vivência dos professores da rede pública no contexto escolar, bem como os impactos na qualidade de vida e na satisfação desses profissionais com relação a seu trabalho. Foram considerados inúmeros aspectos que de certa forma possuem correlação com a saúde mental e física dos docentes, 
visto que a qualidade de vida no trabalho relaciona-se diretamente com a satisfação do trabalhador.

Em decorrência destes dados, os objetivos a serem alcançados por meio deste trabalho foram identificar os possíveis impactos psicológicos causados pelas vivências de professores em seu ambiente de trabalho, na rede pública de ensino no município de Osório-RS. Descrever de que forma o acúmulo de atribuições pode estar associado ao abalo emocional sofrido pelos professores; refletir sobre a desvalorização profissional do professor na sociedade; identificar os possíveis fatores de risco que possam resultar em declínio na qualidade de vida e reconhecer os possíveis fatores de proteção relacionados à qualidade de vida dos professores.

\section{METODOLOGIA}

Participaram do estudo adultos (18 anos e mais) funcionários de escolas municipais do município de Osório, serviço mantido pela prefeitura municipal para atender os habitantes do município de Osório. O estudo desenvolveu os itens do questionário de qualidade de vida no trabalho e incluiu dez professores. Destes, seis professores participaram de entrevistas exploratórias individuais para o desenvolvimento do questionário; os outros quatro professores, individualmente, avaliaram o conteúdo do questionário. Estimou-se que este tamanho de amostra foi suficiente para obter saturação de unidades (ou categorias) significativas (FONTANELLA ET AL 2008; MILES \& HUBERMAN, 1994; PATTON, 1991) das experiências como docente; contudo, a amostra seria aumentada caso o critério de saturação não tivesse sido atingido. Os 10 professores foram escolhidos conforme as seguintes experiências: estar no exercício da atividade docente por no mínimo 5 anos $(n=2)$, estar no exercício da atividade docente há, no mínimo, 10 anos $(\mathrm{n}=2)$, estar no exercício da atividade docente há, no mínimo 15 anos $(\mathrm{n}=2)$, estar no exercício da atividade docente há, no mínimo $20 \operatorname{anos}(n=2)$ e após 25 anos de trabalho $(n=2)$. Eles foram entrevistados individualmente nas escolas, após consentimento informado por escrito. 
Para o desenvolvimento dos itens do questionário, foram realizadas entrevistas exploratórias individuais, baseadas em roteiro temático pré-definido que incluiu:

(a) satisfação com a carreira profissional;

(b) as percepções quanto ao apoio social fora do ambiente de trabalho;

(c) as percepções quanto as relações no ambiente de trabalho;

(e) as percepções e as expectativas - vantagens e desvantagens - de trabalhar como professor;

(f) as percepções quanto à possíveis mudanças na qualidade de vida, como resultado da atividade docente.

A entrevista baseou-se em perguntas semi abertas, facilitando ao pesquisador estabelecer comparações entre sujeitos e, ao mesmo tempo, possibilitando aos entrevistados expressar o entendimento dessas experiências em suas próprias palavras.

As entrevistas foram gravadas e, posteriormente, transcritas para facilitar a análise do seu conteúdo, mas os entrevistados também podiam fazer comunicações com o gravador desligado, se assim o desejassem. Os sentimentos mobilizados na entrevista não foram trabalhados do ponto de vista psicodinâmico, mas o pesquisador demonstrou empatia e compreensão, buscando manter as características informais e situacionais da conversação.

\section{ANÁLISE DOS DADOS}

Foram utilizadas técnicas para analisar os dados resultantes da transcrição, com o objetivo de organizar e compilar o material obtido através das questões respondidas pelos participantes, na tentativa de simplificar a interpretação. A análise de conteúdo foi baseada em (BARDIN, 2011), na qual se organiza em três etapas: pré-análise, etapa em que o pesquisador começa a organizar o material para que ele se torne útil para a pesquisa. Exploração do material: é nesta fase que se realiza a descrição analítica, onde o material textual é submetido a um exame minucioso, norteado pelas hipóteses e referenciais teóricos. O último passo do processo será o tratamento dos dados auferidos e interpretação, é nesta etapa que os o material 
bruto é elaborado para se tornar utilizável. O pesquisador pode elaborar processos estatísticos, básicos ou complexos, que viabilizem concentrar e pôr em evidência as informações fornecidas pela análise (BARDIN, 2011).

\section{CONSIDERAÇÕES ÉTICAS}

Esta pesquisa foi realizada com coleta de dados em escolas municipais do município de Osório. As informações foram coletadas de forma individual de acordo com a demanda, sem qualquer prejuízo para as pessoas envolvidas, principalmente no que diz respeito aos dados pessoais dos participantes. Os dados coletados ficarão sob a guarda do pesquisador (Leonardo Souza Campos) e de seu orientador (Prof. Dra. Zuleika Costa) por cinco anos, sendo garantido seu sigilo e confidencialidade.

Todos os participantes assinaram Termo de Consentimento Livre e Esclarecido para a autorização da coleta e análise dos dados, cientes que as informações geradas serão divulgadas, via relatório e publicações, seguindo os princípios éticos da pesquisa em saúde.

Os princípios de bioética - beneficência, não-maleficência, justiça e autonomia permearam todos os passos deste estudo, assim como a garantia da confidencialidade das informações trazidas pelos participantes (FRANCISCONI \& GOLDIN, 2002). Desta forma, somente a equipe da pesquisa têm acesso ao banco de dados e qualquer informação que possa revelar a identidade dos pacientes será confidencial e tratada com sigilo profissional. As informações confidenciais foram guardadas à parte do banco de dados usado para as análises. No banco de dados os sujeitos foram identificados apenas por letras.

\section{RESULTADOS E DISCUSSÃO}

As entrevistas foram realizadas com dez professores que atuam na rede pública de ensino no município de Osório-RS, com tempo de atuação na profissão docente variando entre 5 e 25 anos. Através da análise dos dados obtidos nas entrevistas foi possível criar três categorias apresentadas a seguir. 


\subsection{Desvalorização profissional}

Na categoria desvalorização profissional procurou-se contextualizar o ponto de vista dos entrevistados com relação a sua atuação na escola, bem como o reconhecimento por parte da sociedade e a importância da sua atividade para a formação acadêmica dos alunos. Buscou-se entender ainda, qual o grau de satisfação desses profissionais e o que eles gostariam que fosse diferente, de modo a poder traçar um panorama mais amplo das suas vivências no exercício laboral.

Os entrevistados apontaram como um dos pontos importantes, a desvalorização profissional por parte dos pais dos alunos e da sociedade de modo geral, como se pode observar na fala a seguir:

“A vantagem de ser professor é poder fazer a diferença na vida de outra pessoa, e a desvantagem é criar expectativas naquilo que não existe, devido à desvalorização profissional (Entrevistado C)."

A valorização dos profissionais da educação abrange qualificação, plano de carreira, carga horária, salários e condições de trabalho, isto é, falar de valorização profissional não é se esquivar desses temas, que, com a administração democrática, constitui a base do profissionalismo dos professores (VIEIRA, 2008). Neste cenário, nos deparamos ainda com a problemática dos planos de carreira e a baixa remuneração, como retrata a fala da entrevistada:

"O salário é defasado e injusto para a atividade, falta de reconhecimento e respeito por toda comunidade escolar, falta de incentivo, carga horária extensa e muito trabalho para fazer em casa (Entrevista $H$ )".

O professor além de ser desvalorizado em sua função, ganha muito pouco, comparando com a importância da sua atividade tendo em vista que em qualquer que seja a profissão, o início de tudo começa na sala de aula.

\footnotetext{
Entre os vários fatores que afetam a condição do professor, deveria ser dada uma atenção muito particular à remuneração, uma vez que, nas condições do mundo atual, outros fatores, como a posição e consideração que a sociedade lhes reconhece e o grau de apreço pela importância das suas funções, estão grandemente dependentes, tal como em outras profissões similares, da situação econômica que se lhes acorda. (UNESCO, 1966, p. 44).
} 
"Enquanto o governo não levar a educação como prioridade, dificilmente mudará o problema. Educação começa com profissionais valorizados. (Entrevistado G)”.

A fala deste entrevistado transfere a culpa para o governo pelo sucateamento da educação no país.

Ocorreu uma deterioração das condições da formação e da prática profissional do professorado no Brasil, hoje tão desvalorizado no próprio universo acadêmico, na mídia e na sociedade em geral. Diversos trabalhos na literatura mundial mostram que ser professor é uma das profissões mais estressantes na atualidade (LIPP, 2012).

"Os impactos são grandes, pois dificilmente se consegue separar os problemas profissionais dos pessoais, afetando a qualidade de vida. Esses impactos são: desmotivação, cansaço mental e físico, irritabilidade, etc. (Entrevistado D)."

O relato do entrevistado D aponta para alguns sintomas decorrentes das condições laborais em que estão submetidos os professores da rede pública de ensino, no atual cenário da educação no Brasil. De acordo com (FERREIRA, 2012). Não solucionar essa questão é propiciar a desvalorização da profissão e submeter os docentes aos altos riscos de desenvolver depressão e esgotamento nervoso, bem como a redução da expectativa de vida após a aposentadoria, devido às condições a que estão submetidos.

\subsection{Múltiplas atribuições do cargo de professor}

Esta categoria foi selecionada devido à grande frequência de relatos dos entrevistados que abordam questões relacionadas a grande demanda que lhes é atribuída durante a jornada laboral, com o objetivo de induzir a reflexão acerca das condições de trabalho destes profissionais.

"O que causou esses problemas foi a quantidade excessiva de atividades que o professor realiza fora do seu ambiente de trabalho, o que demanda muito tempo (Entrevistado D).,

Talvez este seja o maior obstáculo do professor e também o seu desapontamento, neste aspecto, o gestor quando não consegue cumprir e desempenhar o seu papel com 
efetividade perde o total estímulo pelo trabalho, levando a não compreender o sentido e a identidade da função, atribuindo o papel apenas normativo e refutando a incumbência de ser transformador.

\begin{abstract}
Seja em relação à prática médica ou à pesquisa a respeito da saúde, uma primeira observação se impõe de imediato. A reticência maciça em se falar da doença e do sofrimento. Quando se está doente, tenta-se esconder o fato dos outros, mas também da família e dos vizinhos. É somente após longas voltas que se chega, às vezes, a atingir a vivência da doença, que se confirma como vergonhosa: bastou uma doença ser evocada para que em seguida, venham numerosas justificativas, como se fosse preciso se desculpar. Não se trata de culpa no sentido próprio que refletiria uma vivência individual, e sim um sentimento coletivo de vergonha [...] somente em última instância, as doenças são assumidas pelo indivíduo, como um último grito de socorro que ele dá para se safar de situações constrangedoras e dolorosas vivenciadas no ambiente de trabalho (DEJOURS, 2003, p. 29-30).
\end{abstract}

Este é o cenário mais corriqueiro no âmbito escolar, professores enfermos devido a carga psicológica e desgaste físico sem condições laborais, sobrecarregado e exaurido, muitas vezes na relação com os seus familiares e alunos.

“Estar próximo, poder ajudar de alguma maneira é bom. O problema é o excesso de trabalho, inclusive em casa, finais de semana e o estresselansiedade que isto causa (Entrevistado J).”

"Me dedico $100 \%$ para a escola/trabalho, planejamento, reunião, projetos...tempo integral, não consigo fazer nada para mim e minha família (Entrevistado A)”.

O que se acredita que seria um trabalho formador e ideal são aspectos como: atividade estimulante e reflexiva, construtivista, onde é constante a aquisição de novas práticas pedagógicas, amparo psicossocial, condições estruturais para o bom desempenho do trabalho, espaço para atividades de promoção a vida, remuneração condizente com suas necessidades, suporte, auxílio nas intervenções realizadas em sala de aula e relações saudáveis entre todos os indivíduos. A discrepância entre as condições ideias e a realidade do cenário se torna um estímulo para a sensação de impotência, gerando estresse laboral, depressão, entre outras patologias.

\title{
5.3 Educação familiar
}


Esta categoria faz menção a educação previa que os alunos deveriam receber dos pais, e muitas vezes é negligenciada pelos verdadeiros educadores, resultando em alunos indisciplinados e sem limites, como aponta o relato a seguir:

“O aluno, na maioria das vezes não é educado em casa, vem sem limites, o professor tem que ser enérgico, tentar disciplinar, e isso causa mal-estar e desconforto (Entrevistado G) '.

Como explica (FANFANI, 2007), a sociedade exige mais do que a escola pode fazer, ou seja, existe um contraste entre o modelo ideal do papel docente e a realidade refletida na sua prática.

“É correria, acúmulo de funções, fazer papel de professor, psicólogo, enfermeiro, mãe, amiga, etc. (Entrevistada C)."

Esse acúmulo de atribuições ocasiona conflitos, devido à sobrecarga, vê reduzido seu tempo disponível para estudar, participar de cursos ou outros recursos que poderiam agregar na sua qualificação, desfavorecendo seu aperfeiçoamento e sua realização profisssional (ESTEVE, 1999; NACARATO, VARANI e CARVALHO, 2000; SCHNETZLER, 2000).

"Sem dúvida a maior dificuldade é a família, a ausência dela, tudo está a cargo do professor, tudo é culpa do professor, inclusive querem nos atribuir a tarefa de educar. Querem nos nomear "educador". Não aceito este termo, eu, como professora tenho formação para ensinar, educar é papel da família. (Entrevistada E)."

Segundo (JUNCKEN, 2008) a causa do surgimento de doenças físicas e mentais está nas salas de aula cheias, barulho demasiado dentro e fora das salas, desrespeito dos estudantes, acúmulo de tarefas, excesso de pressão da equipe diretiva, péssima infraestrutura, a desvalorização do trabalho e sem dúvidas o baixo retorno financeiro. Somando tudo isso chegamos à causa dos impactos que afetam o corpo e a mente dos profissionais da educação.

O problema relacionado a essas questões têm atingido proporções cada vez mais alarmantes, podendo resultar em patologias graves. A qualidade de vida do professor afeta diretamente a efetividade do seu trabalho e consequentemente reflete no desenvolvimento direto dos seus alunos. (POMIECINSKI E POMIECINSKI, 2014) afirmam que em virtude do 
acentuado estresse laboral que os educadores suportam, eles além de estarem propensos a desenvolverem o fenômeno do mal-estar, também estão vulneráveis a Síndrome de Burnout.

\begin{abstract}
Burnout é uma erosão gradual, e frequentemente imperceptível no início, de energia e disposição, como consequência de um stress crônico e prolongado, ou melhor, de uma incapacidade crônica para controlar o stress. Não acontece como resultado de eventos traumáticos isolados. O Burnout não ocorre de repente; é um processo cumulativo, começando com pequenos sinais de alerta, que, quando não são percebidos, podem levar o professor a uma sensação de quase terror diante da ideia de ter que ir à escola (LIPP, 2012, p. 65).
\end{abstract}

Com isso, é possível enxergar que ao surgir os primeiros sintomas de estresse, ele deve ser tratado, pois muitos profissionais abandonam a profissão porque não suportam lidar com os fatores estressantes, outros continuam, mas esperam ansiosos com a chegada dos fins de semana, as férias e, finalmente, a aposentadoria (LIPP, 2012, p. 66). Com professores enfermos e insatisfeitos é previsto que o nível de qualidade da educação não melhore, porque se os professores não receberem auxílio imediato, provavelmente eles estarão trabalhando desmotivados.

\title{
6 CONSIDERAÇÕES FINAIS
}

O objetivo desta pesquisa foi analisar os principais impactos que afetam a qualidade de vida dos professores da rede pública de ensino no município de Osório-RS, buscando evidências que possam contribuir para a compreensão desta problemática. Pode-se perceber através deste estudo que são inúmeros fatores que causam sobrecarga nos educadores e tornam a rotina difícil e estressante, situação que é acentuada pela remuneração incompatível com a qualificação que eles têm. Nesse aspecto, o professor recorre a acumulação de carga horária, na tentativa de obter um salário condizente com a sua formação. Esses fatores indicam como o professor é desvalorizado e como isso reflete de forma negativa na sua saúde física e emocional. Embora o número de entrevistados deste trabalho seja relativamente pequeno, é possível afirmar através da busca por outras pesquisas, que as análises representam fielmente à realidade das escolas públicas. Não existe uma solução exclusiva para amenizar os efeitos do mal-estar docente, mas por meio do que foi exposto neste trabalho, pressupõe-se que, entre várias alternativas, uma estratégia para modificar esta situação de estresse no trabalho, seja por meio de ações de incentivo e promoção em formações continuadas, no turno em que os professores estão na escola. Um dos maiores obstáculos do âmbito da 
educação é a formação e a valorização do professor, somente através de salários proporcionais ao seu grau de importância na formação do cidadão, planos de carreira decentes e programas de capacitação, é que veremos melhorias na qualidade de vida dos nossos educadores. E para que isso se torne realidade deve-se investir na educação de forma integral, principalmente na capacitação e valorização dos professores. Somente desta forma poderemos ter alunos realmente capacitados, professores motivados e como consequência disso um mundo melhor.

\section{REFERÊNCIAS BIBLIOGRÁFICAS}

BARDIN L. Analise de conteúdo. Tradução de Luis Antero Reto, Augusto Pinheiro. São Paulo: Edições 70, 2011.

BREILH, Jaime. Epidemiologia crítica: ciência emancipadora e interculturalidade. Rio de Janeiro: Editora Fiocruz, 2006.

BREILH, Jaime; TILLERIA, Ylonka. Aceleración y despojo en Ecuador: el retroceso del derecho a la salud en la era neoliberal. Quito: Universidad Andina Simón Bolivar, Ediciones Abya-Yala, 2009.

CORTEZ, Pedro Afonso et al. A saúde docente no trabalho: apontamentos a partir da literatura recente. Cadernos de Saúde Coletiva [on-line], Rio de Janeiro, v. 25, n. 1, p. 113-122, 2017.

CRUZ, Roberto Moraes et al. Saúde docente, condições e carga de trabalho. Revista Eletrónica de Investigación y Docencia, Jaén, n. 4, p. 147-160, jul. 2010.

DEJOURS, C. A loucura do trabalho: estudo de psicopatologia do trabalho. Tradução Ana Izabel Paraguay e Lúcia Leal Ferreira. 5a ed. ampl. São Paulo: Cortez-Oboré, 2003.

ESTEVE, J. M. (1999). O mal-estar docente: A sala de aula e a saúde dos professores. São Paulo: EDUSC.

FANFANI, E. T. Consideraciones sociológicas sobre profesionalización docente. Educação \& Sociedade, Campinas, v. 28, n. 99, p. 335-354, maio/ago. 2007. 
FERNANDES, Eda Conte. Qualidade de vida no trabalho. Salvador, BA: Casa da Qualidade, 1996.

FERREIRA, Gilmar Soares Ferreira. Segunda audiência: educação básica: responsabilidade do Governo Federal? Brasília, DF: Comissão de Educação do Senado Federal, 2012.

FONTANELLA, Bruno José Barcellos; RICAS, Janete; TURATO, Egberto Ribeiro. Amostragem por saturação em pesquisas qualitativas em saúde: contribuições teóricas. Cad. Saúde Pública, Rio de Janeiro , v. 24, n. 1, p. 17-27, jan. 2008 . Disponível em $<$ http://www.scielo.br/scielo.php?script=sci_arttext\&pid=S0102-311X2008000100003\&lng= $\begin{array}{llllll}\text { pt\&nrm=iso }>. & \text { acessos } & \text { em } & 23 & \text { maio } & 2017 \text {. }\end{array}$ http://dx.doi.org/10.1590/S0102-311X2008000100003

FRANCISCONI, C. F.; GOLDIN, J. R. Ética aplicada à pesquisa. Cadernos de Ética em Pesquisa, v.5, n.9, p. 8-9, 2002.

GOES, Carlos Roberto. O SER PROFESSOR NA COMTEMPORANEIDADE: Entre a Utopia de Mudar o Mundo e o Desencantamento com a Realidade.. 2014. 35 f. TCC (Graduação) - Curso de Ciências Sociais, Universidade Federal do Rio Grande do Sul, Porto Alegre, 2014.

GOUVEIA, Andréa Barbosa et al. Condições de trabalho docente, ensino de qualidade e custo-aluno-ano. Revista Brasileira de Política e Administração da Educação, Rbpae, v.22, n.2, p.253-276, dez. 2006. Disponível em: $<$ http://www.seer.ufrgs.br/rbpae/article/download/18883/10998>. Acesso em: 20 abr. 2015.

GOLDBERG, D. P., Gater, R., Sartorius, N., \& Ustun, T. B., Piccinelli, M., Gureje, O., \& Rutter, C. (1997). The validity of two versions of the GHQ in the WHO study of mental illness in general health care. Psychological Medicine, 27(1), 191-197. doi:10.1017/S0033291796004242.

GORENAK, M., \& KOSIR, S. The importance of organizational values for organization. In Management, Knowledge and Learning International Conference PP. 563-569), Slovenia. $\begin{array}{llllll}\text { Recuperado em } & 15 \text { de } & \text { outubro }\end{array}$ de http://www.issbs.si/press/ISBN/978-961-6813-10-5/papers/ML12_117. 
GRANDA, Edmundo; BREILH, Jaime. Saúde na sociedade: guia pedagógico sobre um novo enfoque do método epidemiológico. 2. ed. São Paulo: Cortez, Instituto de Saúde; Rio de Janeiro: Abrasco, 1989.

JUNCKEN, E. As doenças do magistério. 2008. Disponível em: . Acesso em: 09 jun. 2012.

LIPP, M. N. O estresse do professor. $7^{\text {a }}$ ed. Campinas, SP: Papirus, 2012.

MILES, M. B. \& HUBERMAN, A. M. (1994). Qualitative data analysis: an expanded sourcebook. Thousand Oaks: Sage.

MORENO, A. B. et al. Propriedades Psicométricas do Instrumento Abreviado de Avaliação de Qualidade de Vida da Organização Mundial da Saúde no Estudo Pró-Saude. Cad. Saúde Pública, Rio de Janeiro: Dez 2006.

NACARATO, A. M., Varani, A., \& Carvalho, V. (2000). O cotidiano do trabalho docente: palco, bastidores e trabalho invisível abrindo as cortinas. Em C. M. G Geraldi, D. Fiorentina \& E. M. A. Pereira. (Orgs.), Cartografias do trabalho docente (pp.73-104). Campinas: Mercado de Letras.

PATTON, M. Q. (1990). Qualitative evaluation and research methods (2nd ed.). Newbury Park, CA: Sage.

POMIECINSKI, J. A. S.; POMIECINSKI, C. M. Gestão escolar: uma reflexão sobre a saúde emocional do professor - entre o stress e a síndrome de burnout. In: Colóquio Internacional Histórico do artigo: Submetido em: 21/12/2017 - Aceito em: 03/02/2018 10 de Educação, 2014, Joaçaba: Universidade do Oeste de Santa Catarina, Disponível em: https://editora.unoesc.edu.br/index.php/coloquiointernacional/article/download/5188/3160. Acesso em: 30 nov. 2017.

REIS, E. J. F. B., Araújo, T. M., Carvalho, F. M., Barbalho, L., \& Silva, M. O. (2006). Docência e exaustão emocional. Educação \& Sociedade, 27 (94), 229-253. doi:10.1590/S0101-73302006000100011.

SANTOME JT. O professor em época de neoliberalismo: dimensões sociopolíticos de seu trabalho. In: Linhares C (Org.). Os professores e reinvenção da escola: Brasil e Espanha. São Paulo: Cortez; 2001. 
SCHNETZLER, R. P. (2000). Prefácio. Em C. M. G Geraldi, D. Fiorentina \& E. M. de A. Pereira (Orgs.), Cartografias do trabalho docente (pp.7-9). Campinas: Mercado de Letras.

SOUZA, Aparecida N.; LEITE, Marcia P. Condições de trabalho e suas repercussões na saúde dos professores da educação básica no Brasil. Educação \& Sociedade, Campinas, v. 32, n. 117, p. 1.105-1.121, out.-dez. 2011. Disponível em: $<$ http://www.redalyc.org/articulo.oa?id=87321425011> ISSN 0101-7330>. Acesso em: 01 out. 2014 .

SINHA, C. (2012). Factors affecting quality of work life: empirical evidence from indian organizations. Australian Journal of Business and Management Research, 1(11), 31-40.

UNESCO. Recomendação relativa à condição dos professores. Paris: UNESCO, 1966.

VASCONCELOS, Antônio. G. Jurisdição e sofrimento mental: o trabalho é simplesmente locus de manifestação ou um fator concorrente ou constitutivo dos transtornos mentais? Revista do Tribunal Regional do Trabalho da $3^{\text {a }}$ Região, Belo Horizonte, v. 51, n. 81, p. 411-436, jan.-jun. 2010.

VALIZADEH, A., \& GHAHREMANI, J. (2012). The relationship between organizational culture and quality of working life of employees. European Journal of Experimental Biology, 2(5), $1722-1727$.

Recuperado de http://www.imedpub.com/articles/the-relationship-between-organizational-culture-and-qua lity-of-working-life-of-employees.

VIEIRA, Juçara Dutra, Entrevista. In: FORMAÇÃO de professores: impasses e perspectivas. Retratos da Escola, Brasília, DF, v. 2, n. 2-3, p. 15-27, jan./dez. 2008.

WOODS, P. (1999). Intensification and stress in teaching. Em R. Vanderbergue \& M. A. Huberman (Orgs.), Understanding and preventing teacher burnout: A source book of international practice and research (pp.115-138). Cambridge: Cambridge University Press. 